\title{
Sensitivity of cirrus and mixed-phase clouds to the ice nuclei spectra in McRAS-AC: single column model simulations
}

\author{
R. Morales Betancourt ${ }^{1}$, D. Lee ${ }^{2,3}$, L. Oreopoulos ${ }^{3}$, Y. C. Sud ${ }^{3}$, D. Barahona ${ }^{4}$, and A. Nenes ${ }^{1,5}$ \\ ${ }^{1}$ School of Earth and Atmospheric Sciences, Georgia Institute of Technology, Atlanta, Georgia, USA \\ ${ }^{2}$ USRA Goddard Earth Sciences Technology and Research, 10211 Wincopin Circle, Suite 500, Columbia, \\ Maryland 21044, USA \\ ${ }^{3}$ NASA Goddard Space Flight Center, NASA/GSFC, Greenbelt, Maryland 20771, USA \\ ${ }^{4}$ NASA Goddard Space Flight Center, I.M. Systems Group, Maryland, USA \\ ${ }^{5}$ School of Chemical and Biomolecular Engineering, Georgia Institute of Technology, Atlanta, Georgia, USA
}

Correspondence to: A. Nenes (athanasios.nenes@gatech.edu)

Received: 17 May 2012 - Published in Atmos. Chem. Phys. Discuss.: 12 June 2012

Revised: 1 November 2012 - Accepted: 1 November 2012 - Published: 16 November 2012

\begin{abstract}
The salient features of mixed-phase and ice clouds in a GCM cloud scheme are examined using the ice nucleation parameterizations of Liu and Penner (LP) and Barahona and Nenes (BN). The performance of both parameterizations was assessed in the GEOS-5 AGCM using the McRAS-AC cloud microphysics framework in single column mode. Four dimensional assimilated data from the intensive observation period of ARM TWP-ICE campaign was used to drive the fluxes and lateral forcing. Simulation experiments were established to test the impact of each parameterization in the resulting cloud fields. Three commonly used IN spectra were utilized in the BN parameterization to describe the availability of IN for heterogeneous ice nucleation. The results showed large similarities in the cirrus cloud regime between all the schemes tested, in which ice crystal concentrations were within a factor of 10 regardless of the parameterization used. In mixed-phase clouds there were some persistent differences in cloud particle number concentration and size, as well as in cloud fraction, ice water mixing ratio, and ice water path. Contact freezing in the simulated mixed-phase clouds contributed to the effective transfer of liquid to ice, so that on average, the clouds were fully glaciated at $T \sim 260 \mathrm{~K}$, irrespective of the ice nucleation parameterization used. Comparison of simulated ice water path to available satellite derived observations were also performed, finding that all the schemes tested with the BN parameterization predicted average values of IWP within $\pm 15 \%$ of the observations.
\end{abstract}

\section{Introduction}

The role of atmospheric aerosols in modulating the atmospheric radiative balance, by directly scattering solar radiation, or indirectly, by modifying cloud optical and microphysical properties, has received considerable attention during the last couple of decades. Soluble and insoluble aerosol species provide nucleation sites for the atmospheric water vapor to form liquid droplets (Cloud Condensation Nuclei, $\mathrm{CCN}$ ), and ice crystals (Ice Nuclei, IN) respectively. The important interactions between aerosol particles and cloud optical and physical properties operate at temporal and spatial scales unresolved by Global Climate Models (GCMs); their inclusion in climate simulations therefore relies on parameterizations. The importance of these aerosol-cloud interactions, and their potential impact on climate, makes their inclusion in climate models through accurate and physically based schemes a high priority (Intergovernmental Panel on Climate Change, 2007).

Aerosol indirect effects (AIE) in warm clouds have been long studied and implemented in atmospheric models (e.g., Penner et al., 2006), but less has been accomplished for cold clouds. Modifications to the number density and sizes of ice crystals not only strongly affect the radiative properties of ice-bearing clouds, but also impacts the development of precipitation (e.g., Lohmann and Diehl, 2005; Lohmann, 2002). The complexities associated with cold clouds, both mixedphase and ice-only clouds (due in part to the concurrent 
action of different freezing mechanisms, the high selectivity of the IN process, and the theoretical uncertainties associated with their description) have challenged the representation of such clouds in GCMs, most of which lack explicit ice microphysics (Lohmann and Feichter, 2005). As a result, even the sign of the radiative effects of aerosol-ice cloud interactions remains uncertain in climate simulations.

Important steps to improve the simple treatments of cirrus and mixed-phase cloud originally included in GCMs have been undertaken in recent years. For example, the partitioning of cloud condensate between ice and liquid water in mixed-phase clouds $(235 \mathrm{~K} \leq T \leq 273 \mathrm{~K})$ was typically represented by a temperature-only approach (e.g., DelGenio et al., 1996; Rasch and Kristjánsson, 1998). This approach has been progressively replaced by a less empirical and more physically-based representation, in which the deposition growth of cloud ice at the expense of the liquid water, the Bergeron-Findeisen process (Pruppacher and Klett, 1997), is taken into account (e.g., Rotstayn et al., 2000). This prognostic approach for condensate partitioning which includes explicit dependence of the deposition rate on microphysical variables such as ice content $q_{\mathrm{i}}$, and ice crystal concentration, $N_{\mathrm{c}}$, has been adopted by a variety of GCMs (Sud and Lee, 2007; Liu et al., 2007; Salzmann et al., 2010).

Another advancement in GCM cloud schemes is the implementation of two-moment cloud microphysics, which include prognostic equations for the mass as well as number concentration of different hydrometeor categories (e.g., Seifert and Beheng, 2001, 2006; Morrison and Gettelman, 2008). This has permitted the prognostic computation of cloud particles sizes and deposition rates (e.g., Salzmann et al., 2010; Muhlbauer and Lohmann, 2009).

Estimates of the AIE on ice-bearing clouds require an adequate description of the aerosol-cloud coupling through the nucleation process. That is, the prognostic calculation of hydrometeor sizes should be done in a manner consistent to aerosol load changes and aerosol characteristics. However, an efficient and comprehensive representation of the ice nucleation process in the framework of a GCM has proven difficult. Most ice nucleation parameterizations rely on simple functions to determine how many ice crystals will be heterogeneously nucleated at a given set of environmental conditions. These relations describing the availability of IN, termed IN spectra, exhibit different level of complexity, ranging from saturation-dependent schemes (e.g., Meyers et al., 1992; Phillips et al., 2007) to IN spectra with aerosoldependent parameters derived empirically (e.g., Connolly et al., 2009; Niedermeier et al., 2010; Phillips et al., 2008). Theory-based approaches have also led to formulations of IN spectra with explicit dependence on aerosol number concentration, aerosol size distribution, and aerosol surface properties (Khvorostyanov and Curry, 2009; Barahona and Nenes, 2009b; Barahona, 2012). A comprehensive review of IN parameterizations developed from laboratory studies, observations, and theory is provided in Hoose and Möhler (2012).
Most GCM microphysical schemes that account explicitly for aerosol effects represent ice nucleation assuming that there is no variation in ice nucleation properties within an aerosol species. In reality, there is large variability in the ice nucleation properties of aerosol populations, which contributes to the large uncertainty in the predicted IN concentrations.

Homogeneous freezing of deliquesced aerosol (i.e., without the presence of a solid phase) may occur only at temperatures below $235 \mathrm{~K}$, the homogeneous freezing threshold $T_{\text {hom }}$ (Pruppacher and Klett, 1997). For temperatures higher than $T_{\text {hom }}$, in which mixed-phase clouds typically exist, the presence of a solid phase is necessary for ice formation, and therefore only heterogeneous ice nucleation is active. Below $T_{\text {hom }}$, where ice-only clouds form, the supersaturation with respect to ice is the result of the competition between the rate of cooling of the cloud parcel and the deposition on nucleated ice crystals. Since homogeneous and heterogeneous ice nucleation may occur simultaneously, the competition from both mechanisms and their impact on supersaturation further complicate calculations. Therefore, the supersaturation in such situation varies dynamically given the amount of IN present and the dynamical forcing available. For this reason, Lagrangian simulations have been used to develop solutions to the variable supersaturation problem (e.g., Lin et al., 2002), and fits to these numerical solutions have been used to develop ice nucleation parameterizations. A few such parameterizations have been developed (Kärcher and Lohmann, 2002, 2003; Liu and Penner, 2005), and have been implemented in GCM models (Hoose et al., 2010). Analytical solutions to this problem have been developed in which any IN spectrum can be used (Barahona and Nenes, 2009b).

For the case of mixed-phase clouds, liquid water, water vapor, and ice are simultaneously present, and can exhibit complex dynamics (e.g., Korolev, 2007). For the coarse vertical resolution of GCM cloud schemes, the simplifying assumption that the water vapor is saturated with respect to liquid water is sometimes made. The supersaturation with respect to ice, $S_{\mathrm{i}}$, is therefore constrained by thermodynamic equilibrium rather than by the competition of cooling and condensation. With this assumption, it is sufficient to know the availability of IN (given by an IN spectrum) at $S_{\mathrm{i}}$ to compute the nucleation rate of ice crystals.

A number of studies have focused on the implementation and evaluation of new microphysical schemes in GCM simulations, including prognostic calculation of the ice fraction in mixed phase clouds, and using more physically-based ice nucleation schemes (Storelvmo et al., 2008; Sud and Lee, 2007; Liu et al., 2007; Salzmann et al., 2010). Curry and Khvorostyanov (2012) performed a comparison of some heterogeneous nucleations parameterizations in a single-column model for long lived mixed-phase arctic clouds. However, none of these studies has performed sensitivity analysis of the simulated mixed-phase and cirrus clouds fields to different IN spectra. 
In this study, we use the parameterization of Barahona and Nenes (2009b), BN hereafter, in which the ice nucleation problem is treated in a general framework that admits the use of any IN spectra, empirical or theoretical. Barahona et al. (2010) used the BN parameterization to compare common formulations of the IN spectrum in a chemical transport model, finding that the 2 to 3 orders of magnitude variation in the IN concentrations among different schemes would lead to up to a factor of 20 variation in $N_{\mathrm{c}}$ in cirrus clouds. The sensitivity can be even larger in mixed-phase clouds where only heterogeneous ice nucleation is active, and competition for water vapor does not buffer the response of crystal number to IN concentration changes.

Testing the impact of IN spectra in a comprehensive cloud microphysical framework would provide valuable information on how the uncertainties associated with ice nucleation are reflected on the cloud field variables when coupled to other cloud processes. In this study, we report the implementation of the BN ice nucleation scheme into the Microphysics of Clouds with Relaxed Arakawa-Schubert and AerosolCloud interaction (McRAS-AC) (Sud and Lee, 2007) driven by the Goddard Earth Observing System Model, version 5 (GEOS-5). The flexibility provided by the $\mathrm{BN}$ ice nucleation parameterization is ideal for testing the sensitivity of the simulated cloud properties to the representation of IN spectra in the McRAS-AC framework. To isolate the response from the underlying physical parameterization, all the simulations were performed in the Single Column Model version of GEOS-5. This is a common test of GCM microphysics since the SCM configuration contains the same physical parameterizations as the host GCM model, with the advantage of a much smaller computational burden, and the laterally constrained input flux fields allows better delineation of the role of microphysical processes of cloud formation and aerosol effects. The simulations were forced with data collected during the Tropical Warm Pool International Cloud Experiment (TWP-ICE) intensive observation period (IOP) of the ARM program (May et al., 2008), that took place around Darwin, Australia in early 2006.

\section{Model description and simulation set-up}

A detailed description of the McRAS-AC microphysics can be found elsewhere (Sud and Walker, 1999; Sud and Lee, 2007; Bhattacharjee et al., 2010). Here we will primarily focus on describing the treatment of ice-only and mixed-phase clouds microphysics in McRAS-AC.

\subsection{Ice Nucleation in McRAS-AC}

McRAS-AC has the option to invoke either the Liu and Penner (2005), (LP), or the Barahona and Nenes (2008, 2009a,b) parameterizations to describe the ice nucleation process. This capability was used to assess and compare the performance of the two schemes.

The LP parameterization was originally designed to describe the nucleation process at temperatures typical of cirrus cloud formation, i.e., for temperature less than the homogeneous freezing threshold $\left(T_{\text {hom }}=235 \mathrm{~K}\right)$. It is based on numerical correlations derived from statistical fits to a large number of Lagrangian parcel model simulations, in which homogeneous and heterogeneous freezing mechanisms were explicitly accounted for. The homogeneous freezing of deliquesced sulfate aerosol was approached using an effective freezing temperature. Immersion freezing on soot particles was included in the parcel model simulations leading to the LP parameterization by using classical nucleation theory, in which a fixed aerosol size distribution and freezing characteristics were assumed. Deposition freezing is calculated using the Meyers et al. (1992) formulation. In this way, the LP parameterization takes into consideration the impact of updraft velocity, $w$, and aerosol load $N_{\mathrm{a}}$ on the number concentration of nucleated ice crystals, $N_{\mathrm{c}, \text { nuc }}$. In the cirrus regime, it is capable of calculating $N_{\mathrm{c} \text {,nuc }}$ as the result of the competition of both freezing mechanisms. For temperatures above $T_{\text {hom }}$, homogeneous freezing is inactive, and $N_{\mathrm{c}, \text { nuc }}$ is given solely by heterogeneous nucleation. However, because the scheme obtains the number of nucleated ice crystals from curve-fitted functions of temperature and vertical velocity, these specific equations may not hold as well when extrapolated beyond the curve-fit data domain, nor be applied to aerosols that do not follow the prescribed freezing properties used in the simulations.

The implementation of LP in McRAS-AC for mixed-phase clouds ( $T_{\text {hom }}<T<273 \mathrm{~K}$ ) follows closely that of Liu et al. (2007), and was described and tested in a SCM framework (Bhattacharjee et al., 2010). In this regime, $N_{\mathrm{c} \text {,nuc }}$ is calculated by adding the contributions from the numerical correlations described above and the contribution from deposition freezing as given by a modified version of the Meyers et al. (1992) formula,

$N_{\text {id }}\left(S_{\mathrm{i}}\right)=f(z) N_{0} \exp \left(a+b\left(S_{\mathrm{i}}-1\right)\right)$

where $N_{\mathrm{id}}$ is the number concentration of ice crystals due to deposition nucleation in $\mathrm{m}^{-3}, N_{0}=10^{-3} \mathrm{~m}^{-3}, a=-0.639$, and $b=0.1296$, and $f(z)$ is an empirical height correction factor, given by $f(z)=10^{\left(z_{0}-z\right) / \delta z}$, with $z_{0}=1 \mathrm{~km}, \delta z=$ $6.7 \mathrm{~km}$, and $f(z) \in[0.12,1.0]$. This decay factor was derived from observations by Minikin et al. (2003) during the INCA (Interhemispheric Differences in Cirrus Properties from Anthropogenic Emissions) campaign, to augment the formula by Meyers et al. (1992) that was derived from ground-level observations.

In the present work we also implemented and tested the $\mathrm{BN}$ parameterization in McRAS-AC. BN is based on an analytical solution of the governing equations of a cooling air parcel in which deliquesced aerosol and heterogeneous IN are allowed to freeze and grow by water vapor deposition 
(Barahona and Nenes, 2008, 2009a,b). Accordingly, BN circumvents the need for curve-fitted equations, and holds for a wide range of configurations encountered in the physical system. The availability of IN in the BN parameterization can be described with any heterogeneous nucleation parameterizations. Here we use the correlations of Meyers et al. (1992) (MY92), Phillips et al. (2008) (PDA08), and the semi-empirical spectra derived from classical nucleation theory of Barahona and Nenes (2009b), (CNT). MY92 is a widely used, empirical IN spectrum which depends only on $S_{\mathrm{i}}$, which we use here in its original form, without the height correction factor $f(z)$. PDA08 is also empirical, but it considers separately the contribution of organics, dust, and black carbon to the IN population for a given supersaturation. CNT is based on an approximation of classical nucleation theory to calculate IN concentration as a function of supersaturation, and accounts for the impact of aerosol number and freezing properties of different aerosol species to the IN spectrum. For temperatures below $T_{\text {hom }}$, BN calculates the competing effects of homogeneous nucleation on deliquesced aerosol and the heterogeneous freezing for the availability of water vapor in a forming cirrus cloud. The maximum supersaturation with respect to ice attained in the ascending parcel, $S_{\mathrm{i}, \max }$, is calculated by balancing the depletion effect from deposition growth of ice crystals and the availability of water vapor from cooling. In this way, $S_{i, \max }$ is given by the dynamics of cooling and ice nucleation. BN then uses $S_{\mathrm{i}, \max }$ to calculate $N_{\text {c, nuc. }}$.

The application of $\mathrm{BN}$ in the mixed-phase cloud regime differs slightly from that of LP. In the absence of any liquid water, the maximum supersaturation in the parcel would be dictated dynamically by expansion cooling and the IN concentration. However, in McRAS-AC, any initial condensate is considered to be liquid (Rotstayn (1997)) and it is then partitioned following Rotstayn et al. (2000). Therefore, in practice, ice nucleation above $T_{\text {hom }}$ is assumed to occur in an environment saturated with respect to water. Under this circumstance, $S_{\mathrm{i}, \max }$ is fixed by the assumption of water saturation, equal to $S_{\mathrm{i}, \max }=e_{\mathrm{sl}}(T) / e_{\mathrm{si}}(T)$, i.e., the ratio of the saturation vapor pressure over water and over ice, and it is therefore independent of the dynamic forcing, $w$, or aerosol loading. The number concentration of nucleated ice crystals, $N_{\mathrm{c}, \text { nuc }}$, is then calculated by direct application of the IN spectra at the given $S_{\mathrm{i}, \max }$.

\subsection{McRAS-AC cold cloud microphysics}

The cloud microphysics in McRAS-AC include balance equations for the mixing ratios of liquid water, $q_{1}$, and cloud ice $q_{\mathrm{i}}$. The precipitation microphysics are described by Sud and Lee (2007), which recast Seifert and Beheng (2006) to make it applicable to the thicker clouds of a coarse resolution GCM. The activation of aerosol to cloud droplets follows the parameterization of Fountoukis and Nenes (2005). Aerosol mass concentrations are taken from the Goddard
Chemistry Aerosol Radiation and Transport (GOCART), and log-normal size distribution for each species are prescribed, from which aerosol number concentrations are derived.

The partitioning of cloud condensate between ice and liquid in mixed-phase clouds is prognostic, and takes into account the Bergeron-Findeisen (BF) process, by which cloud droplets evaporate and the resulting water vapor deposits onto ice crystals. The process is represented following Rotstayn et al. (2000). The scheme assumes that the water vapor is saturated with respect to liquid water, so that $S_{\mathrm{i}}$ is given by the ratio between the saturation vapor pressure over ice and over liquid water respectively, i.e., $S_{\mathrm{i}}=e_{\mathrm{sl}} / e_{\mathrm{si}}$. Liquid water is evaporated to maintain saturation, so the net process is equivalent to a mass transfer from liquid water to ice. Under the assumption of monodisperse, spherical ice crystals, the rate of change of $q_{\mathrm{i}}$ by deposition is given by

$\frac{d q_{\mathrm{i}}}{d t}=\left(\frac{N_{\mathrm{c}}}{\rho}\right)^{2 / 3} \frac{7.8 q_{\mathrm{i}}^{1 / 3}\left(e_{\mathrm{sl}}-e_{\mathrm{si}}\right)}{\rho_{i}^{1 / 3}(A+B) e_{\mathrm{si}}}$

which explicitly accounts for the dependence of the ice deposition rate on crystal number concentration, $N_{\mathrm{c}}$. In Eq. (2), $\rho$ and $\rho_{i}$ are the densities of air and ice crystals respectively, and $A$ and $B$ represent mass diffusion and heat conduction coefficients associated with the deposition process (Pruppacher and Klett, 1997). Equation (2) is then integrated analytically under the assumption that during one time step, $\Delta t$, all the temperature dependent quantities remain constant, so that over $\Delta t$, the change in $q_{\mathrm{i}}$ is given by,

$\Delta q_{\mathrm{i}}=\min \left[q_{1}, C F\left(\frac{2}{3} c_{\mathrm{vd}} \Delta t+q_{\mathrm{i} 0}^{2 / 3}\right)^{3 / 2}\right]$

where $C F$ is the cloud fraction, and $c_{\mathrm{vd}}$ is a coefficient equal to the left hand side of Eq. (2) divided by $q_{\mathrm{i}}^{1 / 3}$, and $q_{\mathrm{i} 0}$ is the assumed initial mixing ratio of cloud ice. The corresponding temperature increase due to the release of latent heat of fusion is applied to the grid-box mean temperature field.

Ice crystal number concentration $N_{\mathrm{c}}$ is determined in McRAS-AC by the processes of ice nucleation, both by homogeneous nucleation of deliquesced aerosols and heterogeneous ice nucleation, contact freezing of water droplets, melting of cloud ice, and freezing of supercooled water droplets below $T_{\text {hom }}$. The ice nucleation term is calculated with the LP and the BN parameterizations as explained in Sect. 2.1. Contact freezing of supercooled cloud droplets through Brownian coagulation with insoluble IN (mineral dust) is included as given by Young (1974) and Muhlbauer and Lohmann (2009). Ice multiplication processes are not included in the calculation of ice crystal number concentration.

Aerosol input for ice nucleation is also based on GOCART aerosol climatology. A single mode log-normal size distribution was assumed for black carbon, with geometric mean diameter, $d_{\mathrm{g}}=0.04 \mu \mathrm{m}$, and a geometric standard deviation $\sigma_{\mathrm{g}}=2.3$ (Jensen and Toon, 1994). Similarly, sulfate aerosol 
Table 1. Simulations reported in this study. The simulation set-up for all the simulations is identical, and they only differ on the ice nucleation scheme.

\begin{tabular}{lccc}
\hline Simulation ID & Contact Freezing & Ice-only Clouds (cirrus) & Mixed-Phase Clouds \\
\hline LP-CTRL & Yes & Liu and Penner (2005) & Meyers et al. (1992) \\
LP-NoFrzc & No & Liu and Penner (2005) & Meyers et al. (1992) \\
BN-PDA08 & Yes & Barahona and Nenes (2009a) & Phillips et al. (2008) \\
BN-PDA08-NoFrzc & No & Barahona and Nenes (2009a) & Phillips et al. (2008) \\
BN-CNT & Yes & Barahona and Nenes (2009a) & Barahona and Nenes (2009a) \\
BN-MY92 & Yes & Barahona and Nenes (2009a) & Meyers et al. (1992) \\
\hline
\end{tabular}

size distribution is assumed log-normal with $d_{\mathrm{g}}=0.14 \mu \mathrm{m}$ and $\sigma_{\mathrm{g}}=1.5$ (Pueschel et al., 1992). The mass of mineral dust from GOCART is distributed in 3 log-normal modes, with geometric mean diameters of $0.16,1.4$, and $10 \mu \mathrm{m}$ respectively, and geometric standard deviations $\sigma_{\mathrm{g}}$ of 2.1, 1.9 and 1.6 respectively for each mode (D'Almeida, 1987). The density of black carbon was assumed equal to $1 \mathrm{~g} \mathrm{~cm}^{-3}$ while for sulfates, we assumed the density of sulfuric acid $(1.84 \mathrm{~g}$ $\mathrm{cm}^{-3}$ ). Density of mineral dust was assumed equal to $2.5 \mathrm{~g}$ $\mathrm{cm}^{-3}$. A probability distribution function of cloud scale vertical velocity, $w$, was used to represent the local variations of velocity at scales relevant for nucleation. The distribution was assumed to be a normal distribution, with mean, $\bar{w}$, equal to the large scale vertical velocity, and a fixed standard deviation $\sigma_{\mathrm{w}}=0.25 \mathrm{~ms}^{-1}$, consistent with the mean standard deviation observed in the INCA campaign for the cirrus regime (Kärcher and Ström, 2003). The large-scale vertical velocity $\bar{w}$ in our simulations was found to be typically $\sim 0.05 \mathrm{~ms}^{-1}$. The sensitivity to $\sigma_{\mathrm{w}}$ was assessed by varying this parameter between 0.1 and $0.5 \mathrm{~ms}^{-1}$.

\subsection{Forcing data}

The SCM configuration consists of an isolated column of a global circulation model, and is therefore, a 1-dimensional time-dependent atmospheric model. The lateral forcing fields to the 72 pressure levels in the atmospheric columns of GEOS-5 are prescribed from assimilated 4D observational data. For the purpose of this study, we used the forcing from the TWP-ICE intensive observation period (IOP), derived by the Atmospheric Radiation Measurement (ARM) program. It includes data from 17 January to 12 February 2006. This data set has been previously utilized in forcing SCM simulations with the intent of testing ice microphysics for GCMs (Wang et al., 2009a), as well as for comparing simulations produced with bulk microphysical schemes of varying complexity in a cloud resolving model with observational data (Wang et al., 2009b; Lee and Donner, 2011). The TWP-ICE data is ideally suited for testing the representation of cold and mixedphase clouds in models and is a frequently used test case that allows comparison with other existing studies (e.g., Varble et al., 2011; Fridlind et al., 2012). It includes periods domi- nated by deep convective clouds and by persisting layers of cirrus clouds.

\section{Simulated clouds fields}

Table 1 summarizes the simulations considered in this study. The objective of the simulation experiments is to evaluate the sensitivity of the cloud fields to the treatment of ice nucleation. A "control" simulation was performed with the LP ice nucleation parameterization as described above, which has been previously used in the McRAS-AC framework (Bhattacharjee et al., 2010). Other simulation experiments were carried out with the BN parameterization, utilizing three different IN spectra. Two additional simulations were considered, in which the contribution to $N_{\mathrm{c}}$ from contact freezing was neglected (LP-NoFrzc and BN-PDA08-NoFrzc). Sensitivity simulations to the width of the updraft velocity distribution, $\sigma_{\mathrm{w}}$, were performed for the CNT IN spectra. All the simulations share the same lateral forcing fields, surface fluxes, and aerosol input, and they only differ in the treatment of ice formation.

The time-height distributions of the total cloud fraction, $C F$, exhibits the basic features observed during the TWPICE campaign (Fig. 1). In the first period of the intensive observation period (IOP), prior to 25 January 2006, the region was influenced by an active monsoon period characterized by considerable convective activity. From 26 January to 2 February, the monsoon was suppressed, and little convective activity was observed, but high clouds persisted through the period. In the final part of the IOP (3-13 February) the region was increasingly impacted by continental storms, reflected in a renewed increase in the convective activity.

The simulated cloud fields show some differences in the $C F$, particularly the simulation with the BN-PDA08, which shows higher frequency of high $C F$ cells. Common to all the simulations with the $\mathrm{BN}$ scheme is an increase, compared to the LP-CTRL, in the $C F$ for the mixed-phase regime, particularly in the convectively active periods, as shown for two of the simulations in Fig. 3. The resulting simulated $q_{\mathrm{i}}$ fields are shown in Fig. 2. Ice mixing ratios generally reach a maxima in the layer extending from the $0^{\circ} \mathrm{C}$ to the $-38^{\circ} \mathrm{C}$ levels. The overall ice mixing ratios encountered in the LP-CTRL 

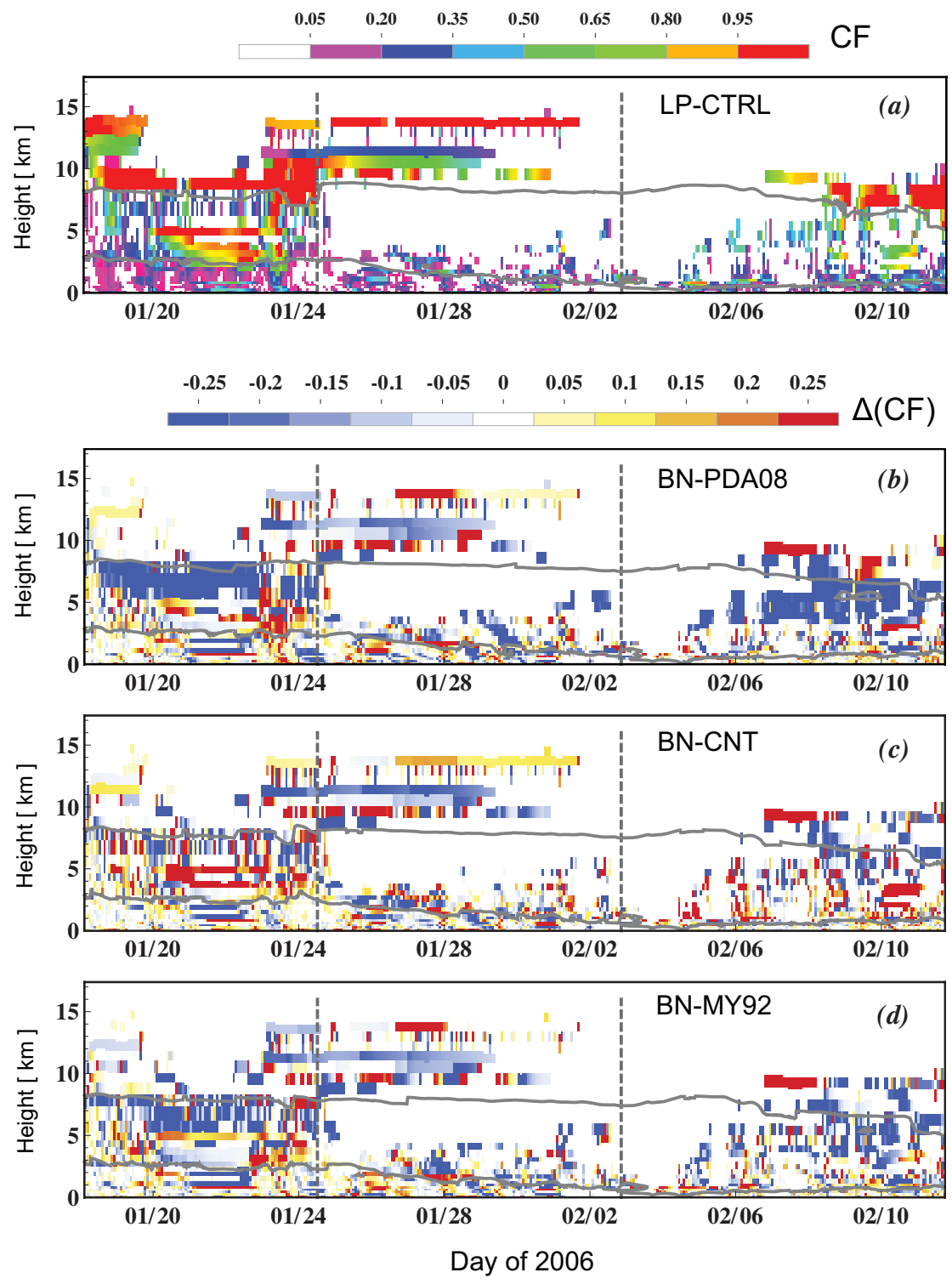

Fig. 1. Time-Height distribution of the simulated cloud fraction for (a) Control simulation with the LP ice nucleation parameterization. (b), (c), and (d) are the differences in the distribution of cloud fraction between the LP-CTRL and simulations performed with BN: (b) for the PDA08 ice nucleation spectra, (c) for the CNT ice nucleation spectra, and (d) corresponds to the simulation with the MY92 ice nucleation spectra. The gray curves correspond to the $0^{\circ} \mathrm{C}$ and $-38^{\circ} \mathrm{C}$ isolines, indicating the region where mixed-phase clouds may occur.

simulation are generally higher than for the BN cases, the difference being more pronounced for the mixed-phase regime.

The temperature dependence of $N_{\mathrm{c}, \text { nuc }}$ and the total ice crystal concentration $N_{\mathrm{c}}$ was calculated from the model output for each one of the simulations as a function of temperature (Fig. 4). Similarly, the dominant transition from heterogeneous dominated freezing at $T_{\text {hom }}$ to homogeneous dominated freezing in the cirrus regime is demonstrated in Fig. 4, as well as the impact of the assumed dynamical forcing on this transition (Fig. 5). The impact of the nucleation scheme in the partitioning of condensate was investigated through the ice fraction, $f_{\mathrm{c}}$, defined as

$f_{\mathrm{c}}=\frac{q_{\mathrm{i}}}{q_{\mathrm{i}}+q_{1}}$.

Figure 6 shows the temperature dependence of the condensate partitioning, for the BN-PDA08, LP-CTRL, BNPDA08-NoFrzc, and LP-NoFrzc. Attention was given to variables affecting the radiative properties of the ice clouds. The size of ice particles would be among the most directly affected variables with changes in crystal concentrations. The behavior of effective radius for ice particles as a function of 

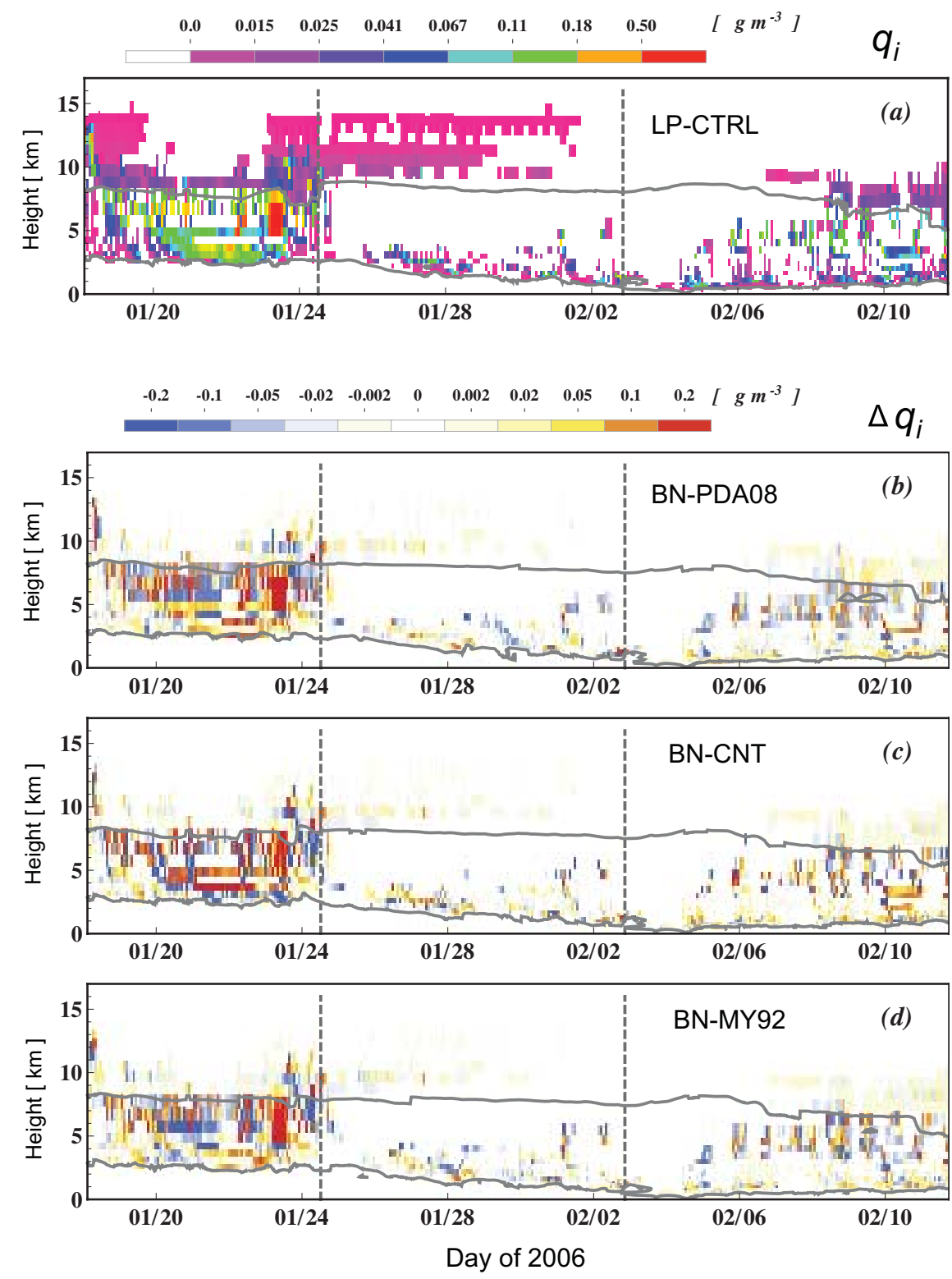

Fig. 2. As in Fig. 1 but for ice mixing ratio in $\mathrm{g} \mathrm{m}^{-3}$.

temperature is shown in Fig. 7 for two of the simulations. Figure 8 shows a time series of IWP from different simulation experiments, together with IWP derived from satellite retrievals from the geostationary satellite MTSAT-1R, using the Visible Infrared Shortwave-Infrared Split-Window Technique (VISST), described in Fridlind et al. (2012).

\section{Discussion of the results}

Since the lateral forcing and surface fluxes were prescribed identically in all simulation experiments, any differences in the cloud fields can be attributed to the interaction of the ice nucleation scheme with the BF process and the cloud mi- crophysical response that follows. Some such differences are encountered between the fields produced with LP and BN parameterization respectively. $N_{\mathrm{c}, \text { nuc }}$ calculated with the $\mathrm{BN}$ PDA08 and BN-MY92 is systematically lower for the mixedphase cloud regime, as compared to LP-CTRL. For the BNCNT simulation, crystal number concentrations show similar values than those in LP-CTRL. In the CNT spectrum, the IN efficiency of mineral dust is accounted for by assuming a high value for the "compatibility parameter", $m$, equal to the cosine of the IN-water contact angle Pruppacher and Klett (1997). For dust it is assumed that $m=0.96$. The contribution of soot to the IN population is much smaller, which is represented in CNT by setting $m=0.76$. 

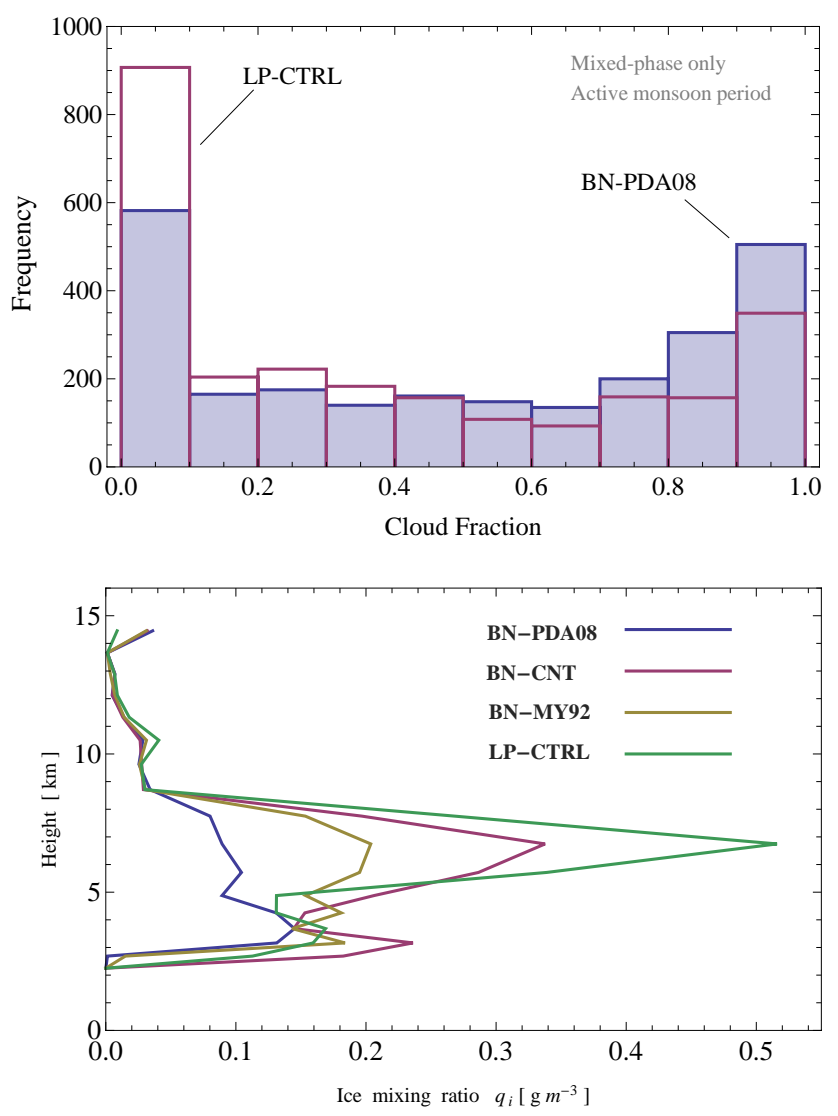

Fig. 3. (a) Histogram of cloud fraction for the LP-CTRL and BNPDA08 simulations. The frequencies are calculated for the active monsoon period and for cells with temperatures in the range $235 \mathrm{~K}<T<273 \mathrm{~K}$. (b) Vertical profile of in-cloud ice mixing ratios averaged over the monsoon active period.

The greatest difference in the number of nucleated ice crystals is found between LP-CTRL and BN-PDA08, for which the maximum difference in the predicted $N_{\mathrm{c}, \text { nuc }}$ can be considerable (Fig. 4). The low concentration of IN predicted by the PDA08 spectrum, typically two orders of magnitude lower than produced by the other spectra, explains part of this difference. However, the systematic discrepancy between LP and BN in the mixed-phase regime is likely due to the different implementation of the two nucleation schemes. As described in Sect. 2.1, the LP scheme adds the contributions from immersion freezing (given by the numerical correlations of Liu and Penner (2005)) and from deposition (as given by Eq. (1)). In the BN schemes the availability of IN in the mixed-phase regime is dictated by the IN spectrum alone, which consider deposition and condensation freezing.

The large differences in predicted $N_{\mathrm{c} \text {,nuc }}$ are also noticeable in the resulting $N_{\mathrm{c}}$ fields, but the magnitude of the difference is significantly lower. In the range of temperatures where contact freezing is active $(270.15 \mathrm{~K}>T>235 \mathrm{~K})$ this mechanism was found to contribute, on average, between $10^{-4} \mathrm{~cm}^{-3}$ and $10^{-3} \mathrm{~cm}^{-3}$ to the ice crystal concentration,
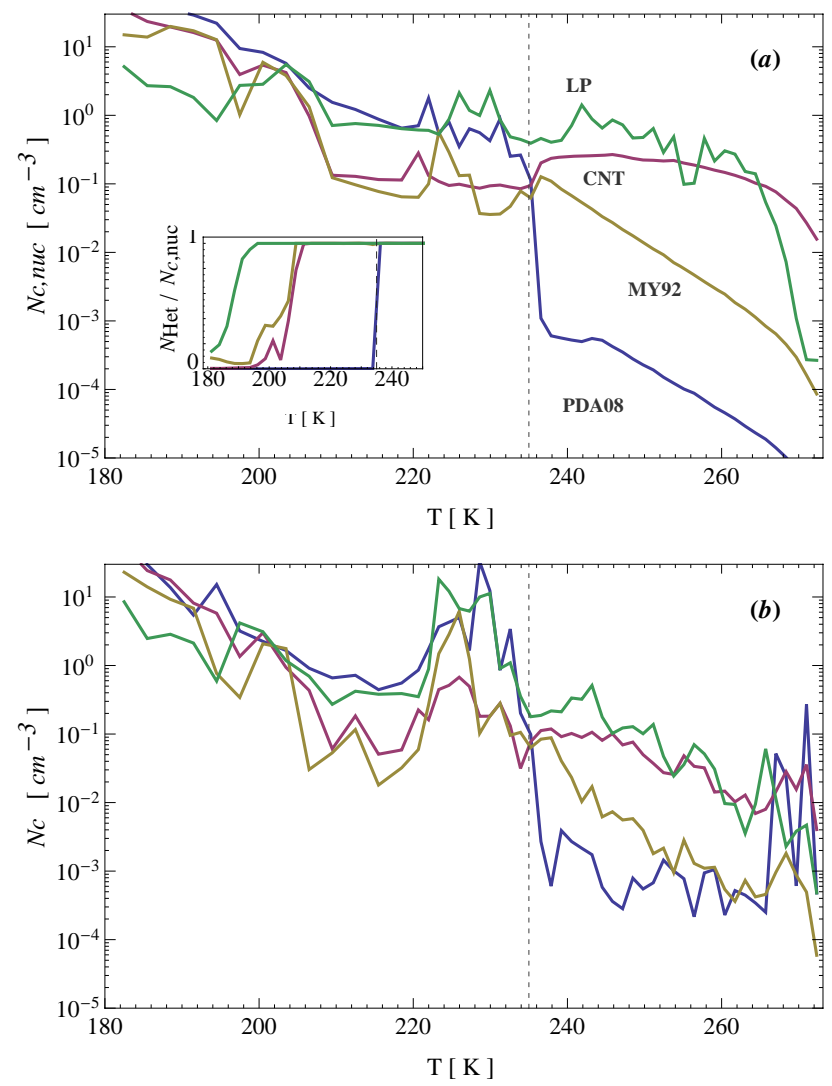

Fig. 4. (a) Average number of nucleated ice crystals, $N_{\mathrm{c} \text {, nuc }}$ as a function of temperature for the simulations considered in this study. The inset is the fraction of crystals nucleated heterogeneously, $N_{\text {het }} / N_{\text {c,nuc }}$. (b) Average number concentration of ice crystals $N_{\mathrm{c}}$ as a function of temperature. The vertical dashed line marks the homogeneous freezing temperature threshold.

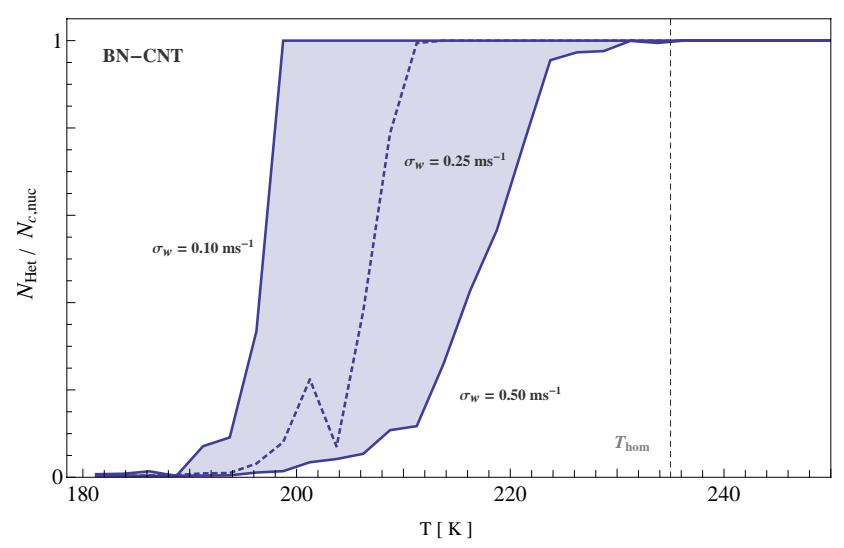

Fig. 5. Average fraction of crystals nucleated heterogeneously, $N_{\text {het }} / N_{\mathrm{c}, \text { nuc }}$ for the BN-CNT parameterization, as a function of temperature for different assumed widths of the probability distribution function of updrafts, $\sigma_{\mathrm{W}}$, ranging from 0.1 to $0.5 \mathrm{~ms}^{-1}$. The vertical dashed line marks the homogeneous freezing temperature threshold. 

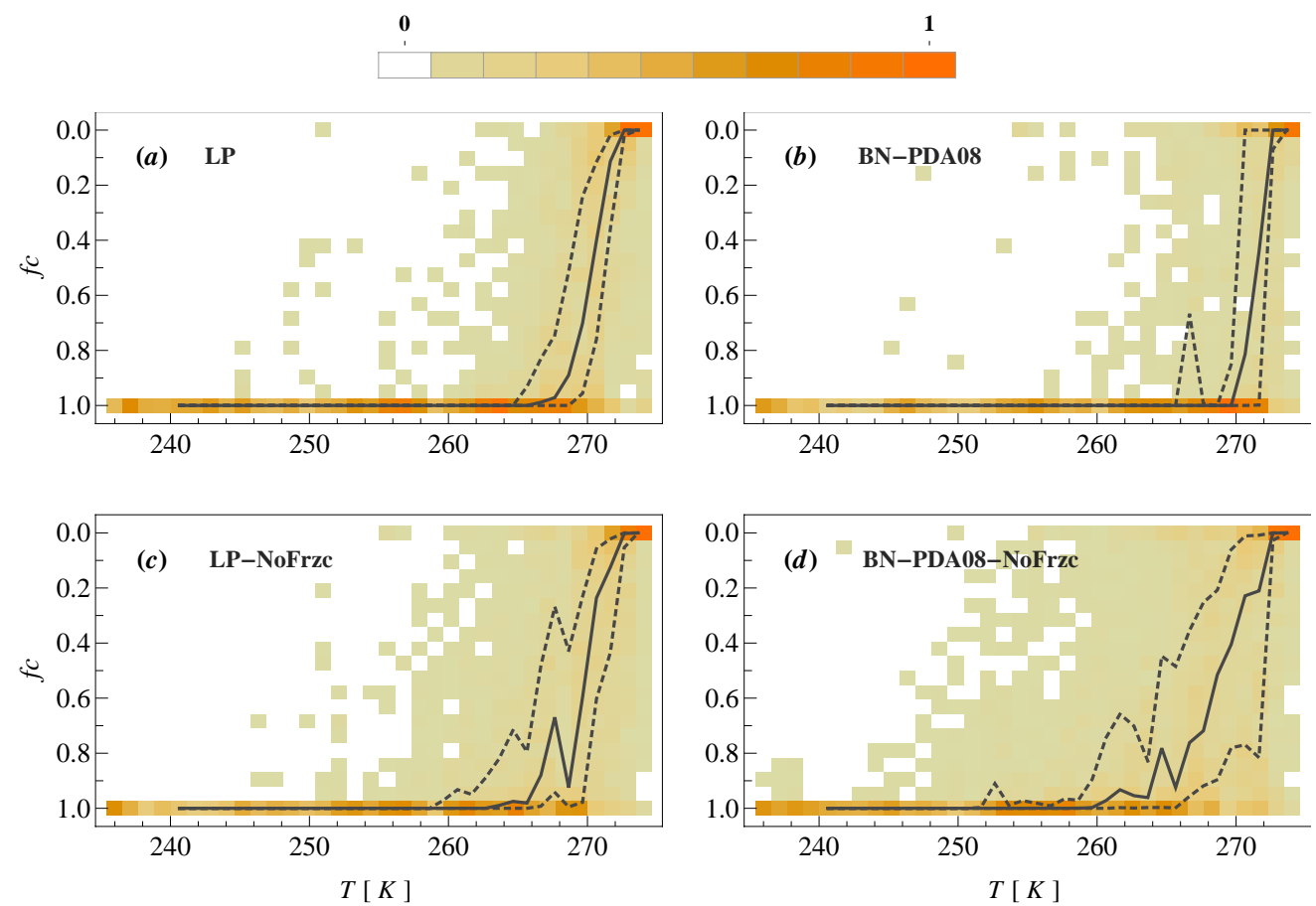

Fig. 6. Frequency distribution of the ice fraction $f_{\mathrm{c}}$ as a function of temperature. The dark grey cruves represent the quartiles of the distribution of $f_{\mathrm{c}}$ corresponding to a temperature interval of $1 \mathrm{~K}$. (a) LP-CTRL simulation, (b) LP-NoFrzc simulation, (c) BN-PDA08 simulation, and (d) the BN-PDA08-NoFrzc.

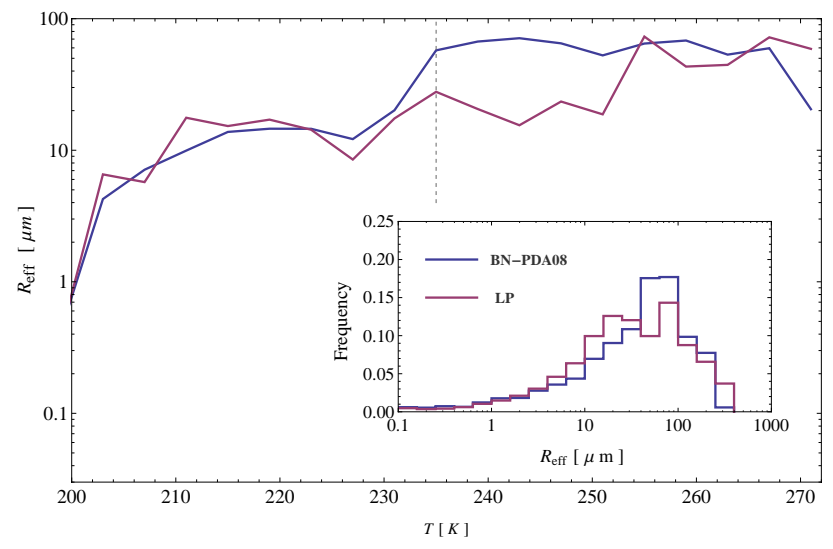

Fig. 7. Median values for the ice crystals effective radius for $\mathrm{BN}$ PDA08 and LP-CTRL. The inset is a histogram of the frequency distribution of the effective radius of ice crystals for the simulated clouds in the mixed-phase temperature regime $(235 \mathrm{~K}<T<273 \mathrm{~K})$. The bins are uniformly separated in logarithmic scale.

thereby effectively providing a lower bound for $N_{\mathrm{c}}$ (Fig. 4). This contribution is significant only for IN spectrum predicting very low $N_{\mathrm{c}, \text { nuc }}$ (such as PDA08), or for the temperatures above $T \sim 260 \mathrm{~K}$, in which the other IN spectrum (MY92 and CNT) predicts very small $N_{\mathrm{c}, \text { nuc. }}$.

It is expected that the differences in $N_{\mathrm{c}}$ would significantly impact other cloud microphysical variables, particu- larly through the modification of the rate of the BF process. Lower ice crystal concentrations should result in lower rates of conversion of liquid water to ice because the surface area for vapor-ice mass transfer is low (Rotstayn et al., 2000). Such behavior, in which low aerosol concentrations are associated with low $f_{\mathrm{c}}$, has been observed in satellite retrievals for the case of dust aerosol (Choi et al., 2010). However, the ice fraction exhibits little to no change across simulations even for the cases where $N_{\mathrm{c}}$ differ by a factor of 100 (Fig. 6a, b). This diminished sensitivity of $f_{\mathrm{c}}$ to ice crystal concentration seems to be caused by the action of the contact freezing mechanism. To verify this, two simulations in which this mechanism was deactivated were performed (LP-NoFrzc and BN-PDA08-NoFrzc), the results of which are shown in Fig. 6c, d. LP-NoFrzc shows that the transition from pure liquid to pure ice cloud occurs over a larger temperature interval as compared to simulations in which contact freezing is allowed to occur. However, because LP predicts relatively large crystal concentrations in the entire range of supercooling temperatures, the BF process is always fast, resulting in a rather similar dependence of $f_{\mathrm{c}}$ on temperature. This is not the case for the simulations with BN-PDA08, in which the low $N_{\mathrm{c}}$ severely limits the rate of conversion of liquid water to ice by water vapor deposition, which is evidenced when contact freezing is deactivated (Fig. 6d).

Satellite data based on polarization measurements and cloud top brightness temperatures retrieved during the 

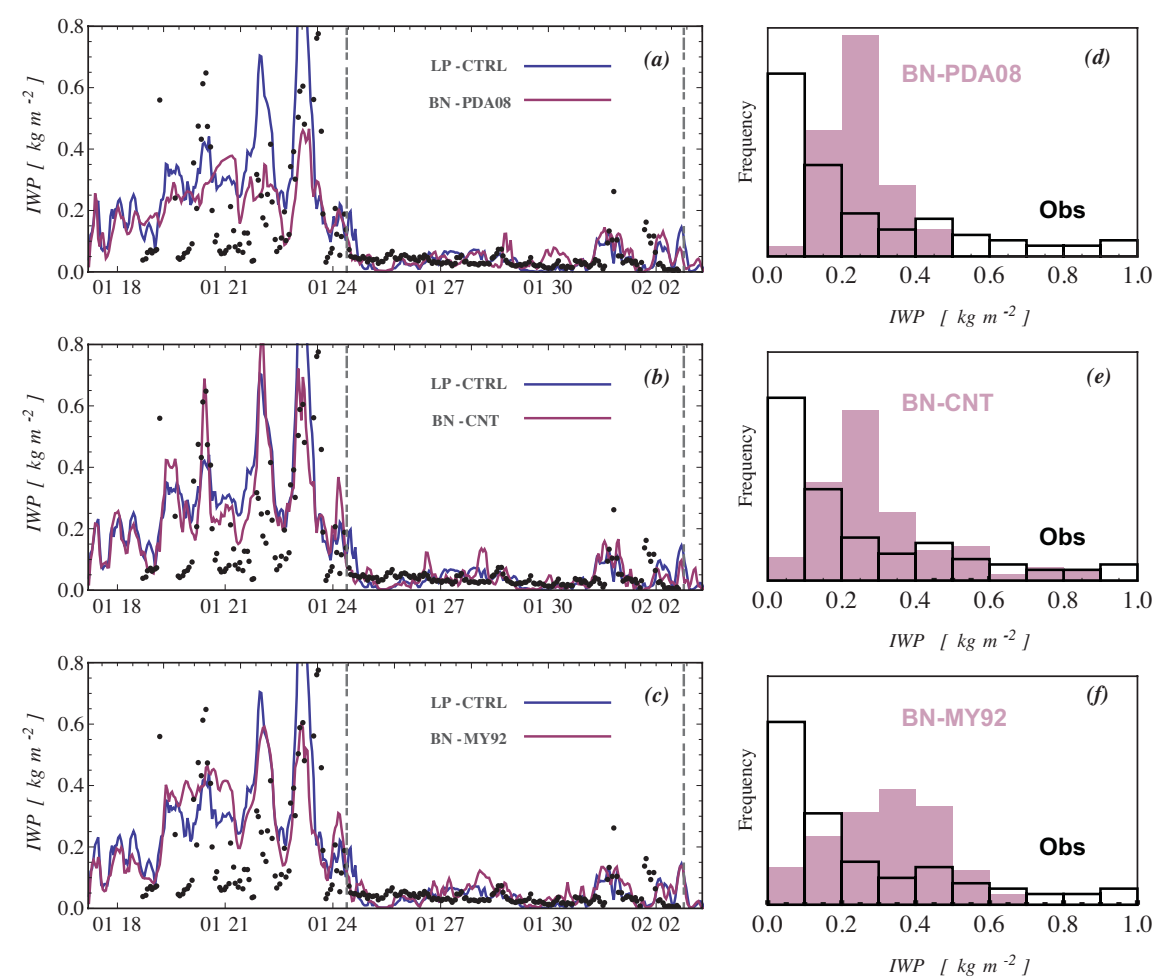

Fig. 8. Ice Water Path (IWP) time series in $\mathrm{kg} \mathrm{m}^{-2}$ from MTSAT-derived data with the VISST technique, and simulated IWP for different IN spectra (a) LP-CTRL and BN-PDA08, (b) LP-CTRL and BN-CNT, (c) LP-CTRL and BN-MY92. The dashed vertical lines denote the initiation and end of the suppressed monsoon period. (d), (e), and (f) are the corresponding relative frequency histograms for the time-series data restricted to the active monsoon period. Black (empty) histograms correspond to observations, while shaded histograms correspond to simulations with $\mathrm{BN}$.

monsoon active period of the TWP-ICE campaign, suggest that liquid-only cloud tops occur at temperatures above 253 $\mathrm{K}$, while only ice-topped clouds are seen at temperatures colder than $T_{\text {hom }}$ (van Diedenhoven et al., 2012). These observations, consistent with similar studies (e.g., Choi et al., 2010), suggest that the simulated glaciation temperatures in our simulations could be too warm, pointing perhaps to an overestimation of the mass transfer to ice from contact freezing. Nevertheless, the narrow temperature range associated with the transition from $f_{\mathrm{c}}=0$ at $273 \mathrm{~K}$ to $f_{\mathrm{c}}=1$ at $260 \mathrm{~K}$ is consistent with other studies with the same partitioning scheme, as well as with available cloud observations of $f_{\mathrm{c}}$ (Rotstayn et al., 2000; Liu et al., 2007). This transition to a fully glaciated state at warmer temperatures has been exhibited by cloud resolving models for the same observation period (van Diedenhoven et al., 2012). For the coarse vertical resolution of a GCM, this rapid glaciation could arise from the assumption that the BF mechanism dominates this regime (Korolev, 2007).

The cloud amount in the mixed-phase regime was affected by the crystal ice nucleation parameterization used in the simulations. As shown in Fig. 3, there is an increase in the frequency of occurrence of cloudy cells with $C F>0.5$ when the BN-PDA08 parameterization is used in place of LP. This is true for the three IN spectra utilized in this study, with $C F$ being $49 \%$ larger for BN-PDA08, and $\sim 25 \%$ for BN-MY 92 and BN-CNT, as compared to simulations with LP.

In the cirrus cloud regime, the difference in $N_{\mathrm{c}, \text { nuc }}$ between LP and BN is less pronounced than in the mixed-phase regime. For this temperature range, crystal concentrations calculated with LP and BN are within one order of magnitude irrespective of the IN spectrum used, which is consistent with the variability reported in previous studies (Barahona et al., 2010). $N_{\mathrm{c} \text {,nuc }}$ for LP-CTRL and BN-PDA08 are in close agreement, however, the predicted mechanism of freezing is different for both parameterizations. Due to the very low IN number predicted with PDA08, the contribution of heterogeneous freezing to $N_{\mathrm{c} \text {,nuc }}$ in BN-PDA08 is negligible, and the process is dominated by homogeneous freezing (Fig. 4). The opposite behavior is observed when LP is used, in which homogeneous freezing only contributes significantly to the $N_{\mathrm{c}, \text { nuc }}$ at extremely low temperatures. When CNT or MY92 are used instead, the lower $N_{\mathrm{c}, \text { nuc }}$ is the result of the depletion of water vapor from the more numerous IN, and homogeneous freezing is triggered only at temperatures between $200 \mathrm{~K}$ and $220 \mathrm{~K}$ (Fig. 4). 
The impact of updraft velocity on the dominant freezing mechanism is exemplified in Fig. 5. When a weak dynamical forcing is applied (e.g., $\sigma_{\mathrm{w}}=0.1 \mathrm{~m} \mathrm{~s}^{-1}$ ), freezing on the available IN rapidly depletes supersaturation, and the resulting dominant mechanism is heterogeneous freezing, implying that colder temperatures are required to enter the homogeneous freezing dominated regime. When the dynamical forcing is stronger (e.g., $\sigma_{\mathrm{w}}=0.5 \mathrm{~m} \mathrm{~s}^{-1}$ ), the available IN cannot deplete supersaturation quickly enough to prevent homogeneous freezing to occur, and the transition to homogeneous freezing occurs even at warmer temperatures. This behavior is shown in the envelope of Fig. 5. Such dependency on updraft velocity was not observed when the PDA08 was used (not shown), because IN concentrations are very low, such that even extremely weak updrafts $\left(\sim 0.05 \mathrm{~ms}^{-1}\right)$ are enough for high supersaturations to be reached, thereby favoring homogeneous freezing as the dominant freezing mechanism (Barahona and Nenes, 2009b).

Finally, even though the impact of $N_{\mathrm{c}}$ on the simulated condensate partitioning is small, the different ice crystal concentration predicted with the parameterizations considered in this study considerably impact the cloud radiative properties. For instance, Figs. 2 and 3 shows the ice mixing ratio for different simulation scenarios. The differences observed translate also into ice water path differences, as well as of the hydrometeor sizes. Figure 7 shows the temperature dependence of the median values of the calculated ice effective radius for BN-PDA08 and LP-CTRL. The inset shows a histogram of the frequency distribution of the effective radius for $\mathrm{BN}$ PDA08 and LP only for the range of mixed-phase temperatures. Due to the much lower $N_{\mathrm{c}}$ predicted by PDA08, the effective radius is shifted from a median of $45 \mu \mathrm{m}$ for BNPDA08, to a smaller size with a median of $32 \mu \mathrm{m}$ in the LPCTRL simulation.

The changes induced in the cloud microphysics by the different IN spectra consequently modify the overall column integrated properties of the cloud fields. Figure 8 illustrates the time series of IWP for the different parameterizations. It is clear that IWP for LP-CTRL is higher than for any simulation with $\mathrm{BN}$, with differences being larger in the periods of convective activity. In fact, the average IWP in the active monsoon period for the LP simulation was found to be $0.30 \mathrm{~kg} \mathrm{~m}^{-2}$, while it was of $0.23 \mathrm{~kg} \mathrm{~m}^{-2}$ for BN-PDA08, and $0.28 \mathrm{~kg} \mathrm{~m}^{-2}$ for BN-CNT and BN-MY92. In the suppressed period, IWP averaged $\sim 0.04 \mathrm{~kg} \mathrm{~m}^{-2}$ in all the simulation experiments. These results compare qualitatively well to the available data of IWP as retrieved from MTSAT data. However, the lower bound in these satellite retrievals tends to be much lower than the simulated IWP, while the peaks during the convective events often exhibit higher values than simulated fields. This marked underestimation of the lower IWP values is shown in the relative frequency histograms of Fig. 8. Ice water path from MTSAT during the active monsoon period averages $0.25 \mathrm{~kg} \mathrm{~m}^{-2}$ and $0.04 \mathrm{~kg} \mathrm{~m}^{-2}$ for the suppressed period.

\section{Summary and conclusions}

The ice nucleation parameterization of Barahona and Nenes (2009b) was implemented in the GEOS-5 McRAS-AC cloud scheme and tested in single column mode forced with TWPICE campaign data. Three different heterogeneous ice nucleation spectra (PDA08, CNT, and MY92) were used in simulations experiments with the BN parameterization framework. The IN concentration predicted by the spectra used in this study varied greatly, with PDA08 predicting very low IN concentrations of around $\sim 10^{-4} \mathrm{~cm}^{-3}$, followed by the much higher IN concentrations predicted with MY92, generally $\sim 100$ times larger than PDA08 at any given temperature. BN-CNT predicted the highest IN concentrations in the mixed-phase regime. These simulation experiments were compared to a control simulation using the LP parameterization, which was found to predict the highest ice crystal concentrations across the simulations.

It was shown that the different schemes used in this study often predicted IN concentrations differing by up to three orders of magnitude. Despite these important differences in IN availability, ice crystal number concentration for cirrus cloud temperatures predicted in all the simulations were found to agree within a factor of 10 . However, the mechanism by which these ice crystal are produced is considerably different; $N_{\mathrm{c}}$ computed with LP was dominated by heterogeneous freezing, while simulations with BN transitioned from heterogeneous to homogeneous dominated freezing at higher temperatures. The dynamical forcing was also shown to be an important component in determining the transition from heterogeneous to homogeneous dominated freezing.

In the regime of mixed-phase clouds, the variations in $N_{\mathrm{c}}$ among simulations with the different nucleation schemes was considerably larger than for the ice-only clouds, with the largest variations being within a factor of $\sim 100$. This larger variability is not surprising, since in the absence of homogeneous freezing, the nucleation schemes strongly depend on the IN nucleation spectra. However, the contribution to $N_{\mathrm{c}}$ from contact freezing of cloud droplets with dust particles of $\sim 10^{-3} \mathrm{~cm}^{-3}$ provided a lower bound on $N_{\mathrm{c}}$, and was effectively the largest contributor to crystal concentration when the PDA08 scheme was used. This contribution to $N_{\mathrm{c}}$ also acted to counteract the very large variations in predicted IN concentrations. This points out the specific need for more studies on the necessary parameters to describe contact freezing accurately.

Similarly, it was also found that the action of contact freezing efficiently transforming cloud water into cloud ice buffered the impact of the large variations of $N_{\mathrm{c}}$ seen across the different simulation experiments on the partitioning of cloud condensate. Ice mixing ratios, however, were strongly affected by the ice nucleation scheme. Accordingly, cloud microphysical variables relevant to radiative properties, such as the effective radius of ice crystals and the ice water path, were impacted by the wide range of $N_{\mathrm{c}}$ predicted. It was 
observed that nucleation schemes that predict lower $N_{\mathrm{c}}$ lead to lower in-cloud ice mixing ratios and ice water path, and considerably larger crystal sizes.

This study highlights the need for detailed cloud microphysical observations to constrain the large uncertainties associated with the ice nucleation process which limit the ability of GCM models to make accurate estimates of the contribution of cold clouds to the overall aerosol indirect effects. Continued development and refinement of ice nucleation schemes capable of accounting correctly for different freezing mechanisms is needed; using the approaches used here will help accomplish this.

Acknowledgements. We acknowledge the JCET/NASA Graduate Summer Research Program in Earth Sciences. A. Nenes acknowledges support from DOE grant DE-SC0007145 and NASA ACMAP grant NNX08AK50G. D. Barahona was supported by the NASA MAP program under WBS 802678.02.17.01.07. Lee, Oreopoulos and Sud were supported by funding from NASA's IDS and MAP programs. Resources supporting this work were provided by the NASA High-End Computing (HEC) Program through the NASA Center for Climate Simulation (NCCS) at Goddard Space Flight Center. The authors also acknowledge the valuable insight from Trude Strovelmo and one anonymous reviewer.

Edited by: J. H. Seinfeld

\section{References}

Barahona, D.: On the ice nucleation spectrum, Atmos. Chem. Phys., 12, 3733-3752, doi:10.5194/acp-12-3733-2012, 2012.

Barahona, D. and Nenes, A.: Parameterization of cirrus cloud formation in large-scale models: Homogeneous nucleation, J. Geophys. Res., 113, D11211, doi:10.1029/2007JD009355, 2008.

Barahona, D. and Nenes, A.: Parameterizing the competition between homogeneous and heterogeneous freezing in cirrus cloud formation - monodisperse ice nuclei, Atmos. Chem. Phys., 9, 369-381, doi:10.5194/acp-9-369-2009, 2009a.

Barahona, D. and Nenes, A.: Parameterizing the competition between homogeneous and heterogeneous freezing in cirrus cloud formation: polydisperse ice nuclei, Atmos. Chem. Phys., 9, 5933-5948, doi:10.5194/acp-9-5933-2009, 2009b.

Barahona, D., Rodriguez, J., and Nenes, A.: Sensitivity of the global distribution of cirrus ice crystal concentration to heterogeneous freezing, J. Geophys. Res., 115, D23213, doi:10.1029/2010JD014273, 2010.

Bhattacharjee, P. S., Sud, Y. C., Liu, X., Walker, G. K., Yang, R., and Wang, J.: Importance of including ammonium sulfate $\left(\left(\mathrm{NH}_{4}\right)_{2} \mathrm{SO}_{4}\right)$ aerosols for ice cloud parameterization in GCMs, Ann. Geophys., 28, 621-631, doi:10.5194/angeo-28-621-2010, 2010.

Choi, Y.-S., Lindzen, R. S., Ho, C.-H., and Kim, J.: Space observations of cold-cloud phase change, PNAS, 107, 11211-11216, doi:10.1073/pnas.1006241107, 2010.

Connolly, P. J., Möhler, O., Field, P. R., Saathoff, H., Burgess, R., Choularton, T., and Gallagher, M.: Studies of heterogeneous freezing by three different desert dust samples, At- mos. Chem. Phys., 9, 2805-2824, doi:10.5194/acp-9-2805-2009, 2009.

Curry, J. A. and Khvorostyanov, V. I.: Assessment of some parameterizations of heterogeneous ice nucleation in cloud and climate models, Atmos. Chem. Phys., 12, 1151-1172, doi:10.5194/acp12-1151-2012, 2012.

D'Almeida, G. A.: On the variability of desert aerosol radiative characteristics, J. Geophys. Res., 92, 3017-3026, 1987.

DelGenio, A., Yao, M., W., K., and Lo, K.: A prognostic cloud water parameterization for global climate models, J. Climate, 9, 270304, 1996.

Fountoukis, C. and Nenes, A.: Continued development of a cloud droplet formation parameterization for global climate models, J. Geophys. Res., 110, D11212, doi:10.1029/2004JD005591, 2005.

Fridlind, A. M., Ackerman, A. S., Chaboureau, J.-P., Fan, J., Grabowski, W. W., Hill, A. A., Jones, T. R., Khaiyer, M. M., Liu, G., Minnis, P., Morrison, H., Nguyen, L., Park, S., Petch, J. C., Pinty, J.-P., Schumacher, C., Shipway, B. J., Varble, A. C., Wu, X., Xie, S., and Zhang, M.: A comparison of TWP-ICE observational data with cloud-resolving model results, J. Geophys. Res., 117, D05204, doi:10.1029/2011JD016595, 2012.

Hoose, C. and Möhler, O.: Heterogeneous ice nucleation on atmospheric aerosols: a review of results from laboratory experiments, Atmos. Chem. Phys., 12, 9817-9854, doi:10.5194/acp-12-98172012, 2012.

Hoose, C., Kristjánsson, J. E., Chen, J.-P., and Hazra, A.: A Classical-Theory-Based Parameterization of Heterogeneous Ice Nucleation by Mineral Dust, Soot, and Biological Particles in a Global Climate Model, J. Atmos. Sci., 67, 2483-2503, doi:10.1175/2010JAS3425.1, 2010.

Intergovernmental Panel on Climate Change, 2007: Fourth Assessment Report: Climate Change 2007: Working Group I Report: The Physical Science Basis, Geneva: IPCC, 2007.

Jensen, E. J. and Toon, O. B.: Ice nucleation in the upper troposphere: Sensitivity to aerosol number density, temperature, and cooling rate, Geophys. Res. Lett., 21, 2019-2022, 1994.

Kärcher, B. and Lohmann, U.: A parameterization of cirrus cloud formation: Homogeneous freezing of supercooled aerosols, J. Geophys. Res., 107, 4010, doi:10.1029/2001JD000470, 2002.

Kärcher, B. and Lohmann, U.: A parameterization of cirrus cloud formation: Heterogeneous freezing, J. Geophys. Res., 108, 4402, doi:10.1029/2002JD003220, 2003.

Kärcher, B. and Ström, J.: The roles of dynamical variability and aerosols in cirrus cloud formation, Atmos. Chem. Phys., 3, 823838, doi:10.5194/acp-3-823-2003, 2003.

Khvorostyanov, V. I. and Curry, J. A.: Critical humidities of homogeneous and heterogeneous ice nucleation: Inferences from extended classical nucleation theory, J. Geophys. Res., 114, D04207, doi:10.1029/2008JD011197, 2009.

Korolev, A.: Limitations of the Wegener-Bergeron-Findeisen Mechanism in the Evolution of Mixed-Phase Clouds, J. Atmos. Sci., 64, 3372-3375, doi:10.1175/JAS4035.1, 2007.

Lee, S. S. and Donner, L. J.: Effects of Cloud Parameterization on Radiation and Precipitation: A Comparison Between Single-Moment Microphysics and DoubleMoment Microphysics, Terr. Atmos. Ocean. Sci., 22, 403-420, doi:10.3319/TAO.2011.03.03.01(A), 2011. 
Lin, R.-F., Starr, D. O., DeMott, P. J., Cotton, R., Sassen, K., Jensen, E., Kärcher, B., and Liu, X.: Cirrus Parcel Model Comparison Project. Phase 1: The critical components to simulate cirrus initiation explicitly, J. Atmos. Sci., 59, 3641-3659, 2002.

Liu, X. and Penner, J. E.: Ice nucleation parameterization for global models, Meteo. Z., 14, 499-514, 2005.

Liu, X., Penner, J. E., Ghan, S. J., and Wang, M.: Inclusion of Ice Microphysics in the NCAR Community Atmospheric Model Version 3 (CAM3), J. Climate, 20, 4526-4547, doi:10.1175/JCLI4264.1, 2007.

Lohmann, U.: Possible Aerosol Effects on Ice Clouds via Contact Nucleation, J. Atmos. Sci., 59, 647-656, 2002.

Lohmann, U. and Diehl, K.: Sensitivity Studies of the Importance of Dust Ice Nuclei for the Indirect Aerosol Effect on Stratiform Mixed-Phase Clouds, J. Atmos. Sci., 63, 968-982, 2005.

Lohmann, U. and Feichter, J.: Global indirect aerosol effects: A review, Atmos. Chem. Phys., 5, 715-737, doi:10.5194/acp-5-7152005, 2005.

May, P. T., Mather, J. H., Vaughan, G., and Jakob, C.: Field research: Characterizing oceanic convective cloud systems, Bull. Am. Meteorol., 89, 153-155, doi:10.1175/BAMS-89-2-153, 2008.

Meyers, M., DeMott, P. J., and Cotton, W. R.: New primary ice-nucleation parameterizations in an explicit cloud model, J. Appl. Met., 31, 708-721, 1992.

Minikin, A., Petzold, A., Ström, J., Krejci, R., Seifert, M., Veltoven, P., Schlager, H., and Schumann, U.: Aircraft observations of the upper tropospheric fine particle aerosol in the Northern and Southern Hemispheres at midlatitudes, Geophys. Res. Lett., 30, 1503-1506, doi:10.1029/2002GL016458, 2003.

Morrison, H. and Gettelman, A.: A new two-moment bulk stratiform cloud microphysics scheme in the Community Atmosphere Model, Version 3 (CAM3) - Part I: Description and numerical tests, J. Climate, 21, 3642-3659, doi:10.1175/2008JCLI2105.1, 2008.

Muhlbauer, A. and Lohmann, U.: Sensitivity Studies of AerosolCloud interactions in Mixed-Phase Orographic Precipitation, J. Atmos. Sci., 66, 2517-2538, doi:10.1175/2009JAS3001.1, 2009.

Niedermeier, D., Hartmann, S., Shaw, R. A., Covert, D., Mentel, T. F., Schneider, J., Poulain, L., Reitz, P., Spindler, C., Clauss, T., Kiselev, A., Hallbauer, E., Wex, H., Mildenberger, K., and Stratmann, F.: Heterogeneous freezing of droplets with immersed mineral dust particles - measurements and parameterization, Atmos. Chem. Phys., 10, 3601-3614, doi:10.5194/acp-10-36012010, 2010.

Penner, J. E., Quaas, J., Storelvmo, T., Takemura, T., Boucher, O., Guo, H., Kirkevag, A., Kristjánsson, J. E., and Seland, O.: Model intercomparison of indirect aerosol effects, Atmos. Chem. Phys., 6, 3391-3405, doi:10.5194/acp-6-3391-2006, 2006.

Phillips, V. T. J., Donner, L. J., and Garner, S. T.: Nucleation Processes in Deep Convection Simulated by a Cloud-SystemResolving Model with Double-Moment Bulk Microphysics, J. Atmos. Sci., 64, 738-761, doi:10.1175/JAS3869.1, 2007.

Phillips, V. T. J., DeMott, P. J., and Andronache, C.: An empirical parameterization of heterogeneous ice nucleation for multiple chemical species of aerosol, J. Atmos. Sci., 65, 2757-2783, doi:10.1175/2007JAS2546.1, 2008.

Pruppacher, H. and Klett, J.: Microphysics of clouds and precipitation, Atmospheric and oceanographic sciences library, Kluwer
Academic Publishers, 2nd rev, and enl edn., 1997.

Pueschel, R. F., Ferry, G. V., Snetsinger, K. G., Goodman, J., Dye, J. E., Baumgardner, D., and Gandrud, B. W.: A Case of Type I Polar Stratospheric Cloud Formation by Heterogeneous Nucleation, J. Geophys. Res., 9, 8105-8114, doi:10.1029/91JD02352, 1992.

Rasch, P. J. and Kristjánsson, J. E.: A comparison of the CCM3 model climate using diagnosed and predicted condensate parameterizations, J. Climate, 11, 1587-1614, 1998.

Rotstayn, L., Ryan, B., and Katzfey, J.: A scheme for calculation of the liquid fraction in mixed-phase stratiform clouds in large-scale models, Mon. Weather Rev., 128, 1070-1088, 2000.

Rotstayn, L. D.: A physically based scheme for the treatment of stratiform precipitation in large-scale models. I: Description and evaluation of the microphysical processes, Q. J. Roy. Meteor. Soc., 123, 1227-1282, 1997.

Salzmann, M., Ming, Y., Golaz, J.-C., Ginoux, P. A., Morrison, H., Gettelman, A., Kramer, M., and Donner, L. J.: Two-moment bulk stratiform cloud microphysics in the GFDL AM3 GCM: description, evaluation, and sensitivity tests, Atmos. Chem. Phys., 10, 8037-8064, doi:10.5194/acp-10-8037-2010, 2010.

Seifert, A. and Beheng, K. D.: A double-moment parameterization for simulating autoconversion, accretion and selfcollection, Meteorol. Atmos. Phys., 59, 265-281, 2001.

Seifert, A. and Beheng, K. D.: A two-moment cloud microphysics parameterization for mixed-phase clouds. Part 1: Model description, Meteorol. Atmos. Phys., 92, 45-66, doi:10.1007/s00703005-0112-4, 2006.

Storelvmo, T., Kristjánsson, J. E., and Lohmann, U.: Aerosol Influence on Mixed-Phase Clouds in CAM-Oslo, J. Atmos. Sci., 65, 3214-3230, doi:10.1175/2008JAS2430.1, 2008.

Sud, Y. C. and Lee, D.: Parameterization of aerosol indirect effect to complement McRAS cloud scheme and its evaluation with the 3-year ARM-SGP analyzed data for single column models, Atmos. Res., 86, 105-125, 2007.

Sud, Y. C. and Walker, G. K.: Microphysics of Clouds with the Relaxed Arakawa-Schubert Scheme (McRAS) - Part I: Design and Evaluation with GATE Phase III Data, J. Atmos. Sci., 56, 31963220, doi:10.1029/2008GL036817, 1999.

van Diedenhoven, B., Fridlind, A., Ackerman, A., and Cairns, B.: Evaluation of hydrometeor phase and ice properties in cloudresolving model simulations of tropical deep convection using radiance and polarization measurements, J. Atmos. Sci., 69, 32903314, doi:10.1175/JAS-D-11-0314.1, 2012.

Varble, A., Fridlind, A. M., Zipser, E. J., Ackerman, A. S., Chaboureau, J.-P., Fan, J., Hill, A., McFarlane, S. A., Pinty, J.P., and Shipway, B.: Evaluation of cloud-resolving model intercomparison simulations using TWP - ICE observations: Precipitation and cloud structure, J. Geophys. Res., 116, D12206, doi:10.1029/2010JD015180, 2011.

Wang, W., Liu, X., Xie, S., Boyle, J., and McFarlane, S. A.: Testing ice microphysics parameterizations in the NCAR Community Atmospheric Model Version 3 using Tropical Warm Pool International Cloud Experiment data, J. Geophys. Res., 114, D14107, doi:10.1029/2008JD011220, 2009a.

Wang, Y., Long, C., Leung, L., Dudhia, J., McFarlane, S., Mather, J., Ghan, S. J., and Liu, X.: Evaluating regional cloud-permitting simulations of the WRF model for the Tropical Warm Pool International Cloud Experiment (TWP-ICE), Darwin, 2006, J. Geo- 
phys. Res., 114, D21203, doi:10.1029/2009JD012729, 2009b.

Young, K. C.: The role of contact nucleation in ice phase initiation in clouds, J. Atmos. Sci., 31, 768-776, 1974. 